\title{
TEXTOPLASMA: LA IMAGEN COMO FANTASMA DE LA ESCRITURA EN LA OBRA DE MARIO BELLATIN
}

\author{
Mariano GARCÍA \\ Universidad Católica Argentina/Conicet \\ ardeo2@gmail.com
}

\section{$\uparrow$} Bellas imágenes de sombras

A la luz de una reflexión acerca de la relación entre texto e imagen, se puede enmarcar el siglo XX entre los proyectos literarios de André Breton y W. G. Sebald, por el distintivo uso que ambos autores han hecho del recurso de intercalar texto con imágenes. Sabemos, por ejemplo, que la imagen, sobre todo fotográfica, es incorporada por el autor surrealista en un intento por suprimir toda écfrasis (lo que en retórica designa la recreación verbal de obras de carácter visual) y evitar así las consabidas descripciones para las que el lenguaje verbal -o quizá más certeramente, los lectoresparecía haberse agotado, sobre todo considerando la formidable competencia narrativa que representó el cine en las primeras décadas del pasado siglo. En efecto, al comienzo de su relato, Breton afirma haber concebido las imágenes en Nadja como reemplazo de las descripciones. No por ello debemos olvidar, empero, que su uso de la fotografía aparece equiparado al valor vanguardista del shock fotográfico generador de «belleza convulsiva» (Foster, 2008: 69 y ss.).

Fue precisamente Hal Foster quien llamó la atención, en su ensayo dedicado al uso de la imagen entre los surrealistas (Belleza compulsiva, 1993), sobre el aspecto ominoso que aporta la iconografía de esta vanguardia histórica, donde la imagen ayuda a afianzar o duplica el efecto siniestro que pretenden producir las palabras. También en Sebald, desde otra búsqueda estética, más existencialista que surrealista, en cualquier caso más trágica que lúdica, las imágenes desestabilizan la narración con su hieratismo evocador, con sus ecos melancólicos que pueden derivar hacia lo lúgubre o lo inhumano. Si los comparamos, el proyecto literario de Sebald aparece como domesticación de la práctica surrealista; en él las imágenes, muchas veces documentales, verifican o acompañan el texto (incluso en su compaginación) si bien algunas de estas imágenes tienen un poder de sugerencia que excede los límites textuales. Aunque en el caso de Nadja (1928), de André Breton, el recurso todavía se mostraba relativamente controlado (mayormente sombrías fotos de París que se limitan a ilustrar el itinerario de los protagonistas), con L'Amour fou (1937), previo paso por Les Vases communicants (1932), Breton da un paso más en la dirección emprendida: las imágenes son más caprichosas, las vistas de París son 
reemplazadas por arte surrealista (Man Ray, Max Ernst, Giorgio de Chirico) y la relación entre texto e imagen, desfasada, resulta más difícil de establecer. Es a partir de la propuesta concreta de L'Amour fou desde donde parece desarrollarse la novela con imágenes en Bellatin. En cualquier caso, lo que resulta incuestionable es que, en mayor o menor medida, en ambas obras se perfila mediante este recurso una relación implícita entre la imagen y la muerte.

Esta relación es expuesta de manera contundente por Hans Belting, para quien la imagen, en sus comienzos prehistóricos, se presenta como sustituto del muerto con la función de cubrir su ausencia, relación que se reaviva con el descubrimiento de la fotografía hacia 1835 cuando el inglés William Henry Fox Talbot (1800-1877) comienza a fijar lo que él mismo caracteriza como «bellas imágenes de sombras» (Belting, 2007: 228, imagen 1) y cuando, no mucho después, se populariza en los Estados Unidos la memorial photography, en donde, a la inversa de la fotografía común, que petrifica al vivo en un gesto muerto, se fotografía a los muertos como durmiendo (Belting, 2007: 230, imagen 2). Del mismo modo, se difunde en la época la fotografía de cementerios, todo lo cual llevó a hablar más tarde de un «efecto tanático» de la fotografía (Belting, 2007: 241, imagen 3).

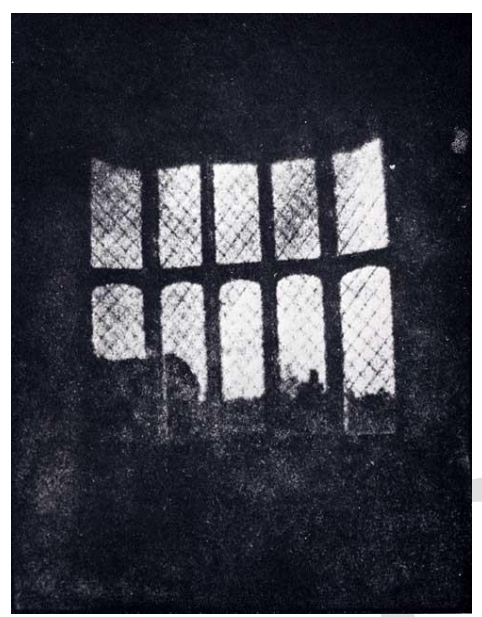

1. Ventana emplomada de la abadía de Lacock (1935) por W. H. F. Talbot

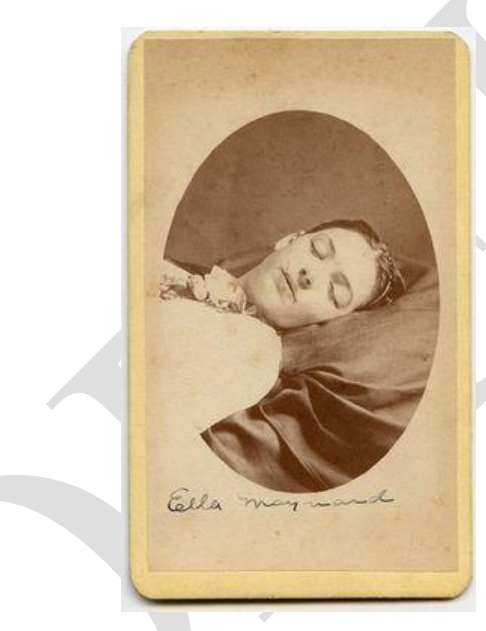

2. Anónimo, Retrato de Ella Maynard, c. 1840

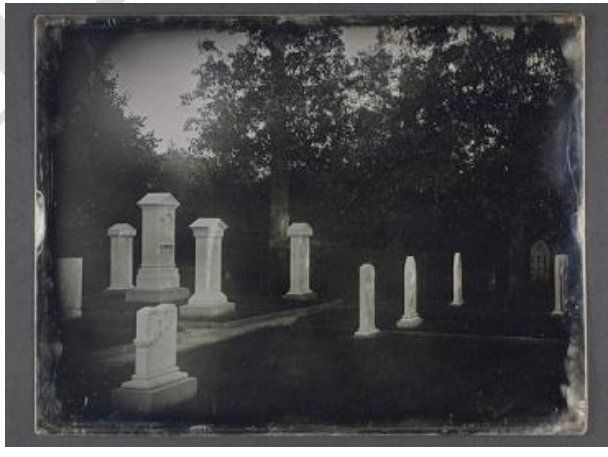

3. Southworth y Hawkes, cementerio de Mont Auburn, c. 1850

\section{Voz e imagen: suplementos de la escritura}

En la obra del peruano-mexicano Mario Bellatin hallamos una incorporación cada vez más decidida de la imagen en el texto, si bien debemos considerar dicho recurso en este escritor como parte de una estrategia más amplia sobre la que volveremos un poco más adelante. Por el momento, respecto de la incorporación de la fotografía en el texto, al menos podemos adelantar la siguiente afirmación de Philippe Dubois (2008:14): «[la fotografía], este medio mecánico, óptico-químico, supuestamente objetivo, del que con tanta frecuencia se ha dicho, en el plano filosófico, que se realizaba «en ausencia del hombre», de hecho, ontológicamente, implica la cuestión del sujeto, y más especialmente del sujeto en proceso». Es evidente, pues, que en gran medida la inclusión de fotografías en la obra de Bellatin se relaciona con, o incluso es consecuencia de, el fuerte componente autoficcional que la caracteriza y 
que también se relaciona con la insistencia de las vanguardias en el proceso por encima del producto o resultado. No resulta así demasiado arriesgado afirmar que la reciente proliferación de ficciones del yo presenta una evidente vinculación con la naturaleza monocular del dispositivo óptico: con su vista de ojo de cíclope, la foto no compone una imagen estereoscópica como la visión humana, generalmente binocular, sino que da del objeto una imagen con punto de vista único (Dubois, 2008: 95). Quizá por eso tampoco resulte casual que la tradición en que se insertan las novelas de Bellatin, como es el caso de los mencionados Breton y Sebald, haya consagrado una especie de diálogo subjetivo entre las ficciones de autor y la imagen fotográfica.

En un autor que pertenece en buena medida a la cultura mexicana no es decir gran cosa que la muerte está presente en muchos de sus textos; sí en cambio llama la atención el papel que cumple la voz como medio mágico para volver presente el pasado. No se trata estrictamente de la evocación de los muertos al estilo de la magia renacentista ni tampoco de la victoriana práctica de las séances espiritistas sino de medios menos ortodoxos. Sin pretensiones de exhaustividad, intentaré mostrar a través de unos pocos títulos el trayecto que recorre en la obra de Mario Bellatin la idea de fantasma como suplemento o «emanación» de la letra, en una evolución particular que va de la voz a la imagen o en el que ambas confluyen.

En Canon perpetuo (1993), novela que ya en su dedicatoria pone el acento en la fotografía, la alienada protagonista acude a una Casa que tiene la peculiaridad de permitir oír a sus clientes distintas clases de voces. «Las había de personajes históricos y de seres anónimos. También de santos y de asesinos» (Bellatin, 2005: 87), aunque lo que ella quiere oír es la voz de su infancia. Los indicios del texto pronto dan a entender que no se trata aquí de algo tan prosaico como una grabación por medios técnicos. Por lo demás, la Casa es un lugar peculiar, mezcla de edificio institucional, burdel y clínica, donde el sistema funciona a través de trueques, mediante los cuales a cambio de la voz que uno pide, debe entregar otras voces. Pese a la nitidez mimética del despojado estilo bellatiniano, la atmósfera del relato se vuelve progresivamente onírica, dejando sugerida en el lector la asimilación de la voz a una suerte de espíritu desencarnado. Las voces vagan por el espacio, se nos sugiere, separadas del cuerpo tal y como podía plantearse en la larga tradición dualista de la metafísica neoplatónica. En ningún momento se insinúa siquiera una explicación sobre la manera de captar esas voces y tenerlas archivadas, salvo quizá por el trato que se le propone a la protagonista: entregar su voz actual y quedarse para el resto de su vida con su voz de niña, pues a ellos les resulta «más importante una voz patológica que una voz infantil» (Bellatin 2005: 110). Sin signos evidentes, solo a través de muy sutiles correspondencias, se puede asimilar esta situación bizarra a una suerte de pacto mágico o incluso diabólico en donde la renuncia a la voz determina una relación metonímica con el alma, según el uso sobre todo romántico de este tópico. A través de su extrañeza, dada por el efecto amortiguado de su tempo onírico, el texto sugiere una atmósfera bastante similar a la de un relato de fantasmas, sugerencia que se corrobora con las recurrencias de la producción posterior.

\section{Las «fotos espectro» en Biografía ilustrada de Mishima}


En efecto, lo que se nos proponía apenas como intuición comienza a manifestarse sistemáticamente unos quince años más tarde con dos obras publicadas en 2009: la Biografía ilustrada de Mishima y Los fantasmas del masajista. Si, por un lado, a lo largo de ese lapso se vuelve habitual tanto la inclusión de imágenes de viejas estampas, objetos y supuestos documentos como en Shiki Nagaoka, una nariz de ficción, así como de fotografías (Perros héroes, Jacobo el mutante) o bien de referencias en los títulos a importantes obras visuales del arte de vanguardia del siglo XX (Lecciones para una liebre muerta en alusión a Joseph Beuys, El gran vidrio en alusión a Marcel Duchamp), en los dos títulos de 2009 converge de manera evidente el tema de la muerte y la imagen, o lo que sería el resultado de esa suma: es decir, el fantasma.

La Biografía ilustrada de Mishima es un ejemplo notable de la capacidad de Bellatin para frustrar las expectativas del lector. Nada de lo que propone el título, de carácter genérico convencional, permite anticipar lo que ofrece el texto. El escritor japonés Yukio Mishima es el protagonista de estas páginas, en efecto, pero lo es después de que le han cortado la cabeza. Según la retórica, esto confiere al Mishima personaje del relato los rasgos de la prosopopeya. Si consideramos la prosopopeya como principio constructivo de la alegoría, su presencia aquí determina, como en gran parte de la producción bellatiniana, la fuerte impronta alegórica de su escritura: esencialización y abstracción nominal a través de un rasgo de los personajes - Poeta Ciego, Nuestra Mujer, etc.- , espacios indeterminados, fragmentación, dialéctica concentración/dispersión, conductas obsesivas, recurrencia de la muerte y del cadáver, membra disjecta, miembros amputados, jeroglíficos, transformaciones, hieratismo y estatismo petrificante propio del melancólico ${ }^{1}$.

Este peculiar Mishima vive en una zona indeterminada entre el mundo de los vivos y los muertos y por allí se pasea sacando unas fotografías que él mismo llama fotos espectro (Bellatin, 2009b: 12) ya que, en la imposibilidad de revelarlas, las fotos existen pero es como si no existieran, vale decir que participan de una naturaleza anfibia análoga a la del protagonista decapitado.

A propósito de la imagen antes de ser revelada, Philippe Dubois (2008: 88) nos recuerda que la imagen latente, siempre imaginaria, es un fantasma de la imagen que no deja de correr todos los riesgos. En la espera de la «Revelación», el espíritu es presa de temores y angustias, aunque poco importa que estén fundadas o sean meramente fantasmales: en ese momento anterior a la revelación no se puede todavía saberlo, necesariamente se encuentra uno en el fantasma. A las vacilaciones simplemente técnicas (¿El encuadre será correcto? ¿No saldrá la imagen movida? ¿No se estropeará el revelado o rayará el negativo?), se agregan indecisiones más esenciales que comprometen la cuestión de la identidad. La imagen latente ¿realmente está ahí? ¿No habrá habido una visión imaginaria, un sueño despierto? Lo que saldrá revelado, ¿será distinto de lo que yo creía?

En ese estado de latencia, en esta distancia, sigue Dubois, se manifiesta toda la relación de la fotografía con la alucinación. Hay un desfase temporal entre el objeto y su imagen, porque ese objeto necesariamente ha desaparecido en el momento en que miro la imagen y por eso mismo comienza a jugar algo fantasmático. La foto aparece entonces como una imagen onírica. Precisamente porque la

\footnotetext{
${ }^{1}$ Cf. Benjamin (2006) y sobre todo Fletcher (1964).
} 
foto es diferida, hendida, agujereada, no deja por ello de ser una imagen fluctuante: fluctúa sobre la certidumbre. De ahí extrae su singular fascinación: si bien sé que en una foto lo que veo estuvo efectivamente ahí, jamás puedo verificarlo realmente, solo puedo dudar (Dubois 2008: 89).

De manera tal vez paradójica, las páginas finales de Biografía ilustrada de Mishima ofrecen muchas de estas fotografías hipotéticas, que en algunos casos son atribuidas a la cámara de infancia con que se nos dice que Mishima retrata los momentos que bordan el relato de sus aventuras de ultratumba, ya que cada imagen lleva una leyenda relativa al texto, aunque la mayoría de las veces la relación entre texto e imagen sea por completo disonante o meramente banal, creando un efecto de ironía retardada, podríamos decir, pues asistimos a la ironización del texto cuando ya hemos terminado de leerlo. En ese sentido, la función de las imágenes parece ser la de un suplemento que socava la certidumbre de un texto ya de por sí incierto.

Las fotografías en la obra de Bellatin pueden asumir una textura estética depurada (como las de Jacobo el mutante, que pertenecen a una fotógrafa profesional); pueden ser fotos de archivo al estilo de Sebald (Shiki Nagaoka) o bien ser fotos de aficionado tomadas por el propio autor, donde toda significación aparece amortiguada por la composición deliberadamente «casual», ilegible (sobre todo con respecto al texto), sin posibilidad de atribución limpia a un significado, es decir, desconcertantemente ambiguas. El lector tiende a considerar así más fidedigno al texto que a la imagen con sus veladuras, grano grueso, encuadres desprolijos, figuras desenfocadas; en suma, una flagrante, provocativa irresponsabilidad de la composición que acaso remita al imaginario iconográfico de nuestro presente de redes sociales.

Como comienza a ser frecuente en la obra de Bellatin, entre las imágenes se despliega la autorreferencia al propio macrotexto, como en la fotografía 15 que alude al Poeta Ciego y su mujer, personajes de un libro anterior de título homónimo. La fotografía 44 es una fotografía real de la cabeza cortada de Mishima; el único elemento que coincide y verifica lo propuesto por el título. Esta inclusión, que es la habitual en Sebald, responde al mecanismo de enriquecer el efecto irreal al servirlo en un marco de elementos miméticos; asimismo responde a la técnica de escamoteo y confusión de los datos de la realidad típica de la obra de nuestro autor. No debemos olvidar que en la obra de Mario Bellatin son recurrentes los espacios-simulacro, lugares nunca explícitamente denotados donde es habitual la idea de una lengua nueva (Schmukler, 2012: 243 y ss.). Esta neutralidad de los lugares puede que responda a los espacios desterritorializados que se nos han vuelto habituales en la era de internet; y acaso se pueda asociar también con lo que se dice del poeta foráneo en Canon perpetuo:

Su drama más grande [...] había sido no poseer una lengua materna. Desde que nació, por razones geográficas y de emigración familiar, había tenido a su alcance distintos idiomas de los que podía escoger las palabras o los modos que más le sirvieran para determinada necesidad. Aquellos resultaba una tragedia a la hora de hacer poemas. Tal vez por eso estaba tan interesado en crear un nuevo lenguaje, exclusivo para la poesía (Bellatin, 2005: 107).

Ese «nuevo lenguaje» puede ser la combinación de la imagen como lengua universal y las peculiaridades del texto tal como lo ofrecerá la literatura posterior de Mario Bellatin, una literatura que se pretende «menor» en el sentido que le dan Deleuze y Guattari. 
Por último, y a modo de curiosidad, la fotografía 48 nos muestra al propio autor, acompañado por una anciana, bajo el epígrafe «pareja de analistas que trabajó el caso Mishima». Aunque se trata de información ajena al texto, la anciana es la madre de César Aira, de quien Bellatin era muy amigo. Esta foto resulta sintomática por su manera indirecta de asociarse o reflejarse en una obra de la que claramente se ha visto influida, así como también por la irrupción de su propia imagen en el espacio ficcional, uno de los motivos clave en la novela del artista o mito personal de Bellatin sobre el que volveremos en breve ${ }^{2}$.

\section{Muerte y voz en Los fantasmas del masajista}

Los fantasmas del masajista se publica el mismo año que el libro sobre Mishima y comparte rasgos tanto intratextuales como extratextuales, puesto que también presenta un considerable material fotográfico reunido al final del volumen y donde las imágenes, borrosas, fuera de foco, con colores saturados, grano grueso, en suma, un deliberado aire «de aficionado», son similares a las de la Biografía ilustrada. También lo es el uso de epígrafes glosados de la narración y la relación no motivada, equívoca, disonante, de cortocircuito, que mantienen con las imágenes. Así como Bellatin frustra las expectativas al presentar un texto radicalmente extraño bajo el título Biografía ilustrada de..., del mismo modo parece trabajar deliberadamente para asignar las fotografías que menos «se parecen» a lo que en principio sugeriría el texto, proponiéndonos así una indagación sobre la producción de imágenes mentales y un cuestionamiento a toda recepción normalizada y paralizante de la narración ${ }^{3}$. Es también muy significativo que las imágenes no vayan intercaladas en el texto, como ocurría con Breton o Sebald, o como todavía ocurría incluso en la misma Jacobo el mutante, sino que se ofrezcan en serie al final, acentuando de ese modo la arbitrariedad que enlaza el texto con la imagen y delimitando dos espacios autónomos, definidos por una relación que parece aspirar a la mutua exclusión. Esta tendencia llegará a su máxima expresión con el concepto de «libro-fantasma», en que las imágenes se presentan ya en un cuadernillo o plaqueta individual.

En el aspecto narrativo, se insiste con el tema de la muerte combinado con la voz. El masajista del título cuenta la historia de su madre, famosa recitadora que a causa de un revés laboral, entra en una depresión. Su hijo, para animarla, le regala un loro hembra que, pese a las vivas recomendaciones del vendedor, no pronuncia palabra (Bellatin, 2009a: 50). La madre muere y su velorio se prolonga por dos días ya que sus colegas le rinden homenaje con largos recitados, y luego sugieren al hijo que no creme el cuerpo pues, como le aseguran, su madre estaba destinada a la resurrección (Bellatin, 2009a: 40). El masajista no les hace caso y por fin, terminado el agotador trámite de la cremación,

\footnotetext{
${ }^{2}$ El mito personal resulta de la combinación de temas, metáforas «obsesivas» y estructuras recurrentes de una obra a otra que permiten esbozar un mapa de la psicología del autor según el método psicocrítico de Charles Mauron. La «novela del artista», según lo teoriza César Aira, es la relación retroactiva entre vida y obra, la fundamentación y alimentación recíproca entre una y otra, que se constituyen a su vez como procesos más que como resultados. Véase Aira (1998 y 2001).

${ }^{3}$ Para una discusión amplia sobre la «guerra de los signos» véase Mitchell (1986), donde la clásica oposición texto-imagen pone en juego los talentos retóricos de ingenio, que busca semejanzas, y juicio, que busca diferencias. Para el tema de la imagen mental, véase ibid., pp. 14-19.
} 
descubre azorado que la lora imita a la perfección la voz de su madre, al punto de que llega a considerar que «el fantasma de la madre muerta está presente en el cuerpo del ave» (Bellatin, 2009a: 68).

João, el masajista, trabaja en una clínica especializada en «personas que han perdido o están por perder algún miembro» (Bellatin 2009a: 73), y estos miembros también son designados como «miembros fantasma», así como el dolor imaginario que producen es un «dolor fantasma». Aunque en este caso no está tematizado el tema de la fotografía ni hay menciones al respecto que motiven su inclusión al final, encontramos en cambio una relación latente entre los miembros-fantasma y la voz fantasma, que al final del texto se revela como el problema del «estorbo del cuerpo», problema del dualismo platónico al que ya aludimos y del que, en la visión bellatiniana, tanto la voz como la imagen parecen escapar ${ }^{4}$.

\section{El fantasma autoficcional}

Disecado (2011) se podría agrupar en tradición menipea de los diálogos de los muertos, con la particularidad de que aquí el autor protagonista habla con su propio fantasma. Llegamos de este modo al momento de máxima exposición autoficcional, que no puede más que rubricarse con la tematización de la muerte del autor. Después de las meticulosas instancias del autodiseño, hay un paso más allá, y es el del suicidio simbólico que representa la muerte del autor (Groys, 2014: 37-47) y que se postula como invariante de la autoficción contemporánea.

Las estrategias que despliega Bellatin para con su figura de autor tienen no pocas características de la imagen que ofrecen de sí los artistas plásticos, ya que la propia obra de Bellatin aspira a salir del estricto marco textual a través de operaciones habituales en el mundo de las artes ${ }^{5}$.

Hay una relación estrecha entre el arte vanguardista y la fotografía, sobre todo en el ready-made, el body art, el art performance y todo lo que tiene que ver con la instalación, que en general se pueden considerar formas radicalizadas de la lógica del índex: el referente en cuanto tal, en su materialidad espacio-temporal, se convierte por sí mismo en su propia representación. La proximidad física entre el signo y su objeto se vuelve identificación total. El contenido de la obra resulta totalmente evacuado: la obra no nos dice otra cosa que lo que la convierte en obra: lo que importa no es el producto o el resultado sino el acto mismo por el cual algo ocurre: acto tanto del artista como del espectador. Se trata de experiencias que realizan una especie de absoluto de la lógica indicial (Dubois, 2008: 106-7).

Por su parte, para Jacques Ranciere (2007: 18-9) entre el simbolismo y el constructivismo (18801920) se establecen diversos modos de un proyecto de arte liberado de las imágenes, liberado no solo de la antigua representación sino de la nueva tensión entre la presencia desnuda y la escritura de la historia sobre las cosas, y liberado al mismo tiempo de la tensión entre las operaciones de arte y las

\footnotetext{
${ }^{4}$ Véanse Lovejoy (1930) y el capítulo 4 de la I Parte de Arendt (1971).

${ }^{5}$ Véase al respecto Reinaldo Laddaga (2010: 29-55). Si bien pese a las pretensiones de objetividad su «lista» de autores autoficcionales es incompleta y personal, y pese a que tampoco aborda la obra de Bellatin, lo menciono porque Laddaga establece un paralelo entre literatura y artes plásticas que resulta pertinente para este trabajo. Desde un plano puramente literario resulta más comprensiva la perspectiva de Julio Premat (2009) sobre lo que él denomina «figuras de autor». Para la relación entre fotografía y autoficción merece consultarse el artículo de Remo Ceserani (2015).
} 
formas sociales de semejanza y reconocimiento. Este proyecto asumió dos formas principales: el arte puro, concebido como arte cuyos resultados ya no componían imágenes, sino que realizaban la idea en una forma material autosuficiente, o arte que se realizaba aboliéndose a sí mismo, que abolía la distancia de la imagen de manera de identificar sus procedimientos con las formas de una vida completa en acción, sin separar ya el arte del trabajo o la política. Debemos entender que es en esta segunda forma que se inscribe la propuesta bellatiniana.

Bellatin ha realizado perfomances a partir de textos suyos (Perros héroes); ha organizado un congreso con dobles de escritores y ha sido curador invitado en la Dokumenta de Cassel; asimismo explota su propia imagen como cuerpo-para-el-trabajo y hace de su brazo-fantasma y de su colección de prótesis una de sus firmas más reconocibles (Laddaga, 2010: 11-13). Aunque involuntario, el símbolo de la mano derecha remplazada por prótesis es de una fuerza icónica que Bellatin supo convertir en algo estético y simbólicamente productivo: las referencias, alusiones o reelaboraciones en torno a su antebrazo faltante son numerosas y están diseminadas en varios de sus títulos.

Así como capta algo muy actual en su forma de referir los lugares, en la manipulación de las imágenes en sus textos y en la presentación verbal y visual de sí mismo, también ha olfateado cierto estancamiento en el mundo editorial al que intenta sacudir con su proyecto de Los Cien Mil Libros de Bellatin y donde la imagen de autor juega un papel tanto o más importante que los textos propiamente dichos.

Como afirma Boris Groys (2014: 47), hoy es más conveniente proclamarse autor muerto que autor maldito, pues esto ayuda a presentar la obra como resultado de una colaboración democrática y porque así la obra se libera de la mirada paralizante de un público no participativo.

El propio título, Disecado, alude irónicamente a la detención de todo proceso, a la fijación o estabilización interpretativa contra la que se levantan las prácticas vanguardistas. Por eso no parece casual que en este caso el autor prescinda de fotografías. Desde el momento en que la imagen-índex pretende inscribirse de manera permanente, conservarse en la memoria, desde el momento en que la imagen pretende superar su referente, eternizarlo, congelarlo en la representación y por lo tanto ocupar su lugar, como huella detenida de su ineluctable ausencia, entonces esa imagen pierde una parte de lo que hacía su pureza indicial: pierde su conexión temporal. El índex se independiza parcialmente. Se abre a la iconización, es decir, a la muerte. La fijación iconizante, al matar la indexación del tiempo referencial, señala el comienzo del trabajo de muerte en la representación. La representación momifica (Dubois, 2008: 113) pero el juego propuesto quiere ir más allá de esa momificación: se pretende dialógico en el sentido trascendente que le otorga Bajtín.

Pero Disecado en último análisis parece solo la excusa para repasar los ya varias veces repasados temas o características de sus obras, una visita guiada que poco tiene para agregar al lector habitual de sus ficciones. Como ocurre con tantos proyectos artísticos modernos surgidos de la larga sombra de Marcel Duchamp, parece de rigor para todo hijo de la vanguardia presentar su boîte-en-valise, aquella obra singular en la que Duchamp ofrecía, miniaturizadas dentro de una valija, las obras que jalonaban 
su carrera. La pregunta es ¿hasta cuántas boîte-en-valise es recomendable hacer en literatura sin producir un efecto de monotonía?

Aunque la deriva artística de las últimas décadas nos enseñó a replantear la relación entre original y copia e incluso que cada ejemplar de una edición tiene su individualidad (Duchamp en México, de Aira), sería válido preguntarse por la relación diversa que guarda una imagen, que infinitamente repetida es, para los parámetros de hoy, recreada más que devaluada y un texto que, dejando de lado su reproducción mecánica en serie, se repite además «artesanalmente» de un título a otro.

En tal sentido, Boris Groys (2014: 63-4) cuestiona la validez de la tesis de Benjamin sobre la reproducción porque esta percibe el espacio de circulación masiva de la copia como un espacio universal, neutral y homogéneo e insiste en la recognoscibilidad visual de la identidad de la copia como tal según el modo en que circula en nuestra cultura. Sin embargo, en el marco de la cultura contemporánea, una imagen circula permanentemente de un medio a otro y de un contexto cerrado a otro contexto cerrado, transformándose en su paso de un lenguaje a otro. La copia deja así de ser una mera copia y se vuelve una imagen en continua transformación.

La poética bellatiniana es una poética del fragmento y para entrar en su mundo y descubrir su significación es necesario tener al menos un atisbo de varios títulos. Así como una palabra tiene una significación acotada fuera de la oración, un título suelto de Bellatin no se termina de completar fuera de una visión abarcadora de la obra; vale decir, el macrotexto como sintaxis, típico del concepto de oeuvre. El problema es si esa obra acaso no se está autoexplicando y reflejando a sí misma con insistencia prematura.

\section{El libro y su fantasma}

Contra los parámetros de toda la obra previa, El libro uruguayo de los muertos aparece como un proyecto de largo aliento, unas 280 páginas en apretada tipografía cuya portada reproduce una de las varias fotografías sacadas por el autor y a las que se refiere innumerables veces a lo largo del texto. Las fotos no aparecen aquí ni intercaladas ni al final del texto, sino que están reproducidas en una plaqueta que se regaló a los compradores de los primeros ejemplares. Este cuadernillo lleva el significativo título de «Libro-fantasma de El libro uruguayo de los muertos», y epitomiza la búsqueda, si se quiere, llevada a cabo por la voz, la relación conflictiva con el cuerpo y la posibilidad de ser un ente desencarnado. La acumulación semántica del título de la plaqueta es evidente al respecto. Para Bellatin el texto es el cuerpo (y el cuerpo, como se vio, es un estorbo) y la voz o la imagen, como en este caso, el alma de un posible relato: es decir su texto fantasma ${ }^{6}$. El mismo narrador nos saca de dudas a las pocas páginas de comenzado este Libro de los muertos en una imagen que remite a Disecado:

Creo que ya entiendo por qué utilizo ahora las fotos en mis libros. Me parece que para apreciar de una manera directa lo irreal en lo que estamos atrapados. Para mirar con tranquilidad los fantasmas, los tiempos

\footnotetext{
${ }^{6}$ Una obra casi contemporánea a la de Bellatin que también se asoma a nociones parapsicológicas y paranormales es la del uruguayo Mario Levrero. Véase Vecchio (2015).
} 
paralelos, los vivos y los muertos comiendo de un mismo plato de arroz y que suelen aparecer en mi cuarto justo antes de que me vaya a dormir (Bellatin 2012a: 10).

Esta dualidad está asimismo presente en la misma fotografía, que también tiene un alma, su negativo antes de ser revelado (Bellatin 2012a: 21). También aquí vuelve Bellatin a repasar su obra, insistiendo particularmente en cómo varias de sus creaciones llevadas al teatro o hechas performance cobran un sentido pleno o terminan de revelar su verdad. De este modo, la escritura se presenta definitivamente como algo incompleto, que no alcanza a transmitir todo su sentido: a su manera, también, un negativo pero de orden material, prosaico, concreto, una cárcel, la cárcel del lenguaje. Si imagen y voz son los dos atributos del espíritu sin cuerpo que se presenta como «fantasma», en Mario Bellatin imagen y voz aspiran a superar el «estorbo del texto». En su asimilación implícita textocuerpo, el cuerpo del texto es un estorbo de la imaginación.

También en esto se revela el talante platónico de Bellatin, que se ubica así en la larga tradición de desprecio a la escritura inaugurada por el Fedón y de cuya crítica la filosofía de Jacques Derrida hizo su carta de presentación. Pese a su modernidad formal, en gran medida sostenida por la propia presencia del autor a través de una conspicua autofiguración intra y extratextual, el contenido de la obra bellatiniana, sus ideas, no resultan actuales sino que invocan la metafísica de la presencia, posible residuo de los estudios teológicos que se acreditan en el currículum de Bellatin. Su escritura tiene una apariencia moderna aunque sus ideas parecen algo reñidas con lo auténticamente nuevo.

La introducción al Libro-fantasma insiste en esa idea:

[Las fotos] terminan de decir lo que la escritura planteó y está imposibilitada, por su carácter mismo de abstracción, de concluir. Les es difícil, por ejemplo, mostrar de un solo golpe lo simultáneo en el tiempo y en el espacio. La relación entre lo vivo y lo muerto. La convivencia de lo falso con lo verdadero (Bellatin 2012b: 4).

Afirmación bastante discutible, tanto como su constatación de que cada vez escribe peor y saca mejores fotos. La alegoría, modalidad que se encuentra en la base de toda su obra, así como las diversas figuras retóricas relacionadas (oxímoron, paradoja, antítesis, ironía), es una manera varias veces secular de transmitir en palabras estos opuestos en convivencia. Pero si él mismo dice estar aburrido de escribir, habrá que conformarse con sus fotos, y pensar que su obra es, también en ese sentido, en su abandono de la letra por la imagen, una ilustración enfática y algo redundante de los tiempos.

\section{Bibliografía}

AIRA, César (1998): Alejandra Pizarnik. Rosario, Beatriz Viterbo.

- (2001): Las tres fechas. Rosario, Beatriz Viterbo.

ARENDT, Hannah (1971): The Life of the Mind. Nueva York, Harcourt.

Bellatin: Mario (2005). Obra reunida. México, Alfaguara.

- (2009a): Los fantasmas del masajista. Buenos Aires, Eterna Cadencia.

- (2009b): Biografía ilustrada de Mishima. Buenos Aires, Entropía.

- (2011): Disecado. Barcelona, Sexto Piso. 
(2012a): El libro uruguayo de los muertos. Pequeña muestra del vicio en el que caigo todos los días. Barcelona, Sexto Piso.

- (2012b): Libro-fantasma de El libro uruguayo de los muertos. Barcelona, Sexto Piso.

Belting, Hans (2007): Antropología de la imagen. Buenos Aires, Katz.

BenJAmin, Walter (2006): El origen del «Trauerspiel» alemán, en Obras libro I / vol. 1. Madrid, Abada.

CESERANi, Remo (2015): «Fotografía y literatura. La memoria, el recuerdo, la reliquia», en Mariano García, María José PunTE y María Lucía PuPPO, comps., Espacios, imágenes, vectores. Desafíos actuales de las literaturas comparadas. Buenos Aires, Miño y Dávila.

Deleuze, Gilles - GuatTARi, Felix (1975): Kafka. Pour une littérature mineure. París, Minuit.

DuBOIS, Philippe (2008): El acto fotográfico. Buenos Aires, La Marca.

FletCHER, Angus (1964): Allegory. The Theory of a Symbolic Mode. Ithaca/Londres, Cornell University Press.

Foster, Hal (2008): Belleza compulsiva. Buenos Aires, Adriana Hidalgo.

GROYS, Boris (2014): Volverse público. Las transformaciones del arte en el ágora contemporánea. Buenos Aires, Caja Negra.

LADDAGA, Reinaldo (2010): Estética de laboratorio. Estrategias de las artes del presente. Buenos Aires, Adriana Hidalgo.

Lovejoy, Arthur O. (1930): The Revolt against Dualism. An Inquiry Concerning the Existence of Ideas. Baltimore, W.W. Norton.

Mauron, Charles (1963) : Des métaphores obsédantes au mythe personnel. París, José Corti.

Mitchel, W. J. T. (1986): Iconology: image, text, ideology. Chicago, The University of Chicago Press. Premat, Julio (2009): Héroes sin atributos. Figuras de autor en la literatura argentina. Buenos Aires, Fondo de Cultura Económica.

RANCIÈRE, Jacques (2007): The Future of Image. Londres, Verso.

SCHMUKLER, Enrique (2012): Fictions en quête d'auteurs: figures d'auteur chez César Aira, Mario Bellatin, Roberto Bolaño et Enrique Vila-Matas. Doctorat d'études hispaniques et latinoaméricaines. Université Paris 8.

VECCHIO, Diego (2015): El inconsciente telepático: los inconscientes de Mario Levrero. Tesis inédita para la HDR. Université Paris 8. 